Austral Comunicación

ISSN (e) 2313-9137 ISSN (I) 2313-9129

Volumen 9, número 1 - Junio de 2020.

\title{
Escándalos y silencios: Las noticias políticas delante y detrás del poder
}

\author{
Noelí Cristti \\ noelicristti@gmail.com \\ Universidad Nacional de Lomas de Zamora \\ Natalia Aruguete \\ nataliaaruguete@gmail.com \\ Conicet, Universidad Nacional de Quilmes \\ Nadia Koziner \\ nadiakoziner@gmail.com \\ Conicet, Universidad Nacional de Quilmes
}

doi: https://doi.org/10.26422/aucom.2020.0901.aru

El doctor Robert Entman ha estado abocado a la investigación y la enseñanza de Políticas Públicas, Periodismo y Comunicación en distintas universidades estadounidenses desde 1980. Actualmente, se desempeña como profesor de Medios y Asuntos Públicos y de Asuntos Internacionales, en la Escuela de Medios y Asuntos Públicos de la Universidad George Washington, en Estados Unidos. Es autor de decenas de libros y sus investigaciones han sido publicadas en revistas académicas norteamericanas y europeas de alto impacto.

Entman es considerado el padre de los estudios de Framing. Sus aportes teóricos constituyen una referencia insoslayable para cualquier investigador que procure profundizar en el análisis de la creación y circulación de los encuadres en el ámbito político, el mediático y el de la ciudadanía. Crítico del periodismo estadounidense, este autor pone en cuestión la extendida idea de la independencia de la prensa e indaga, a su vez, las relaciones entre los medios y el poder político, que dan lugar a las definiciones de la situación oficiales en materia de política nacional e internacional.

Desde su punto de vista, el funcionamiento del sistema democrático está fuertemente vinculado con el ejercicio de un periodismo de calidad. En noviembre de 2019, Entman brindó la conferencia magistral de cierre de la II Jornada de Comunicación Estratégica de la Universidad Nacional de Lomas de Zamora (UNLZ). Durante su estadía, y en el marco del Proyecto Lomas CyT "Cobertura Mediática del Conflicto de Docentes Universitarios", este académico encabezó un conversatorio con investigadores de distintas universidades argentinas, luego del cual concedió la entrevista que compartimos. 


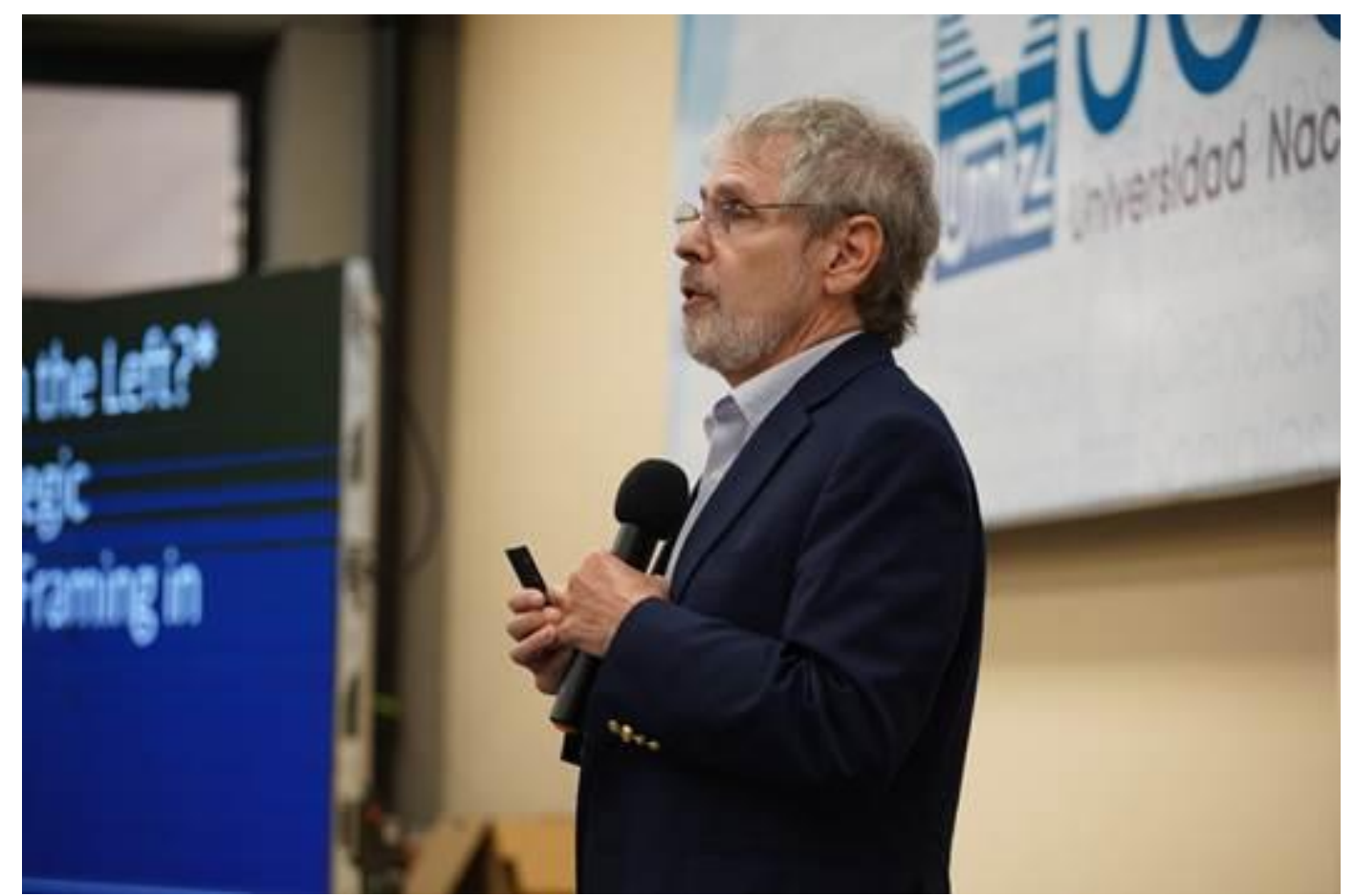

Robert Entman, en la Segunda Jornada de Comunicación Estratégica, el 8 de noviembre de 2019. (Foto: Martina Rico, Secretaría de Coordinación Institucional de la Universidad Nacional de Lomas de Zamora).

\section{Framing, ¿un paradigma fracturado?}

Desde sus primeros trabajos, Entman encuentra en e/ Framing el valor de ser una teoría integral que permite atender la relación entre el comportamiento estratégico de los políticos, los procesos productivos de los periodistas con sus sesgos cognitivos, y las conductas de los votantes y sus esquemas individuales de percepción. Ello supone reconocer que los frames - huellas que e/framing process deja en las distintas etapas de la comunicación- están presentes en la instancia de producción de la información, en los textos noticiosos, en los receptores de dichas noticias y en la cultura, donde hay un repertorio compartido de patrones de cognición e interpretación que provee el vínculo entre producción y recepción de noticias. Aun cuando observa la riqueza teórico-epistemológica que sustenta alFraming, advierte como problemática la "conceptualización dispersa" que se ha hecho de los términos framing, frame y esquema, en distintos estudios a lo largo de estos años. Por ello caracteriza al Framing como un "paradigma fracturado", cuyas piezas desperdigadas no se integran en una guía consistente para la investigación, lo cual impide arribar a una conceptualización inequívoca, una "declaración general" de esta teoría (Entman, 1993, p. 51).

\section{¿Por qué usted considera que el Framing es la teoría apropiada para el estudio} de la producción y circulación de discursos?

Intenté comprender el mensaje, así como la información inserta en los textos y llegué a la conclusión de que el Framing es el mejor enfoque. La preocupación que orientó mi trabajo de 1993 era que, hasta ese momento, cada estudio que proponía un análisis del contenido de los medios utilizaba sus propias definiciones de la acción de encuadrar, de modo que la acumulación de esas 
conceptualizaciones dispersas impedía arribar a una comprensión acabada y consistente de la definición de la situación que predomina en los textos noticiosos. En ese trabajo, propuse recurrir a conceptos únicos que nos guiaran en la búsqueda de conexiones entre las palabras alrededor de algunas de las cuatro funciones del encuadre ${ }^{[1]}[N$. de las $A$.: las funciones del encuadre referidas por Entman son: a) definir efectos o condiciones como problemáticas; b) identificar sus causas; c) emitir un juicio moral, y d) promover un remedio o emitir un pronóstico]. Estas nos permiten exponer al framing como un ejercicio del poder que encauza la interpretación del mundo social por parte de las personas. Creo que he ayudado porque muchos estudios las utilizan, lo que no quiere decir que lo hagan con el mismo sentido que yo lo propuse. Si esta u otra definición de encuadre no alcanza ese objetivo, habrá que buscar otro concepto que tenga ese valor y sea consistente.

Esa consistencia a la que se refiere, ¿sugiere la posibilidad de aplicar su definición a estudios que se llevan a cabo en otros contextos socioculturales?

Creo que en algún lado expresé que ese concepto se desarrolló en el contexto estadounidense. Sin embargo, pienso que los principios generales deberían poder aplicarse en otras regiones con algunas modificaciones locales. Hasta ahora, no había pensado si podría funcionar en otras culturas, ustedes tendrían que contármelo. Sé que hay personas que lo utilizan, que lo adoptaron en algunos países. Creo que la estructura básica es similar, todos los países tienen una mediación para definir las situaciones a través de las redes sociales y/o los medios de comunicación.

\section{Tal vez la cuestión resida en diferenciar entre framesy guiones...}

Puede ser. Sin duda, en diferentes culturas políticas, existen rituales diferentes ciertas cosas que decir y que hacer-, que son coherentes con su propio sistema y que varían según el lugar. Entonces, se pueden esperar diferentes guiones. Por ejemplo, en Italia, donde existe tanto cinismo sobre el gobierno y la democracia, tal vez esté bien que el primer ministro diga que no le importa lo que piense la opinión pública porque sabe qué es lo mejor para el país. Quizás, en Italia no existe el concepto de "el pueblo italiano" —donde está presente el conflicto entre el Sur y el Norte italiano- como sí existe en Estados Unidos el de "el pueblo estadounidense".

Como respuesta al uso indistinto que los académicos de las ciencias sociales hacen de los términos "encuadre", "esquema", "guión" e "imagen", cual si fueran sinónimos, Entman (2004) establece una diferencia conceptual entre estas nociones, asumiendo que ello mejoraría la comprensión académica de/framing como proceso integral. El autor propone utilizar el término "guión"(script) para referirse a los modelos estandarizados de procesamiento de información que los periodistas utilizan para cubrir los asuntos de interés público. Nos referimos puntualmente a una serie de encuadres noticiosos genéricos -"conflicto", 
"consecuencias económicas", "interés humano", "moralidad" y "atribución de responsabilidad"-, inicialmente propuestos por Neuman, Just \& Crigler (1992) y consolidados por Semetko \& Valkenburg (2000), y Peter, Semetko \& de Vreese (2003), entre otros. En los términos de Entman (2004), la diferencia entre los "guiones" y los "encuadres" reside en que los primeros encauzan las historias, mientras que los segundos van más allá, pues promueven interpretaciones que conducen a evaluaciones morales al tiempo que proponen un tipo de tratamiento para los acontecimientos relatados (Entman, 2004). El "esquema", por su parte, se refiere a las estructuras de pensamiento preexistentes que influyen y guían el procesamiento e interpretación de la información por parte de las audiencias (Scheufele, 1999). Así, la interacción entre frames y esquemas asume que el énfasis en determinados aspectos de una realidad percibida activa determinados "trenes de pensamiento" entre las audiencias (Price \& Tewksbury, 1997). Por último, el concepto de "imagen" se ha utilizado en referencia a los modos en que las audiencias almacenan y procesan las analogías. Si de Comunicación Política se trata, Entman sugiere recurrir a la noción de "imagen" para el análisis de ilustraciones visuales no verbales.

\section{El Framing y los paradigmas de la comunicación}

Diversos investigadores trabajan en pos de dotar a/ Framing de una mayor solidez teórica y capacidad operativa. Desde una perspectiva metateórica, D'Angelo (2012) madura la concepción de integralidad desde la doble acepción de "encajar"(fit-into) y "reunir"(bring together). La mayoría de los trabajos se inscriben en la concepción de reunir, al enfocarse en la capacidad que e/framing process tiene de trazar una pintura completa del proceso comunicacional (Matthes, 2012). Las miradas centradas únicamente en esta dimensión, discute D'Angelo, evidencian la "fragmentación" que sufre la teoría (Entman, 1993), y esgrimen la necesidad de una postura unificada y totalizadora del proceso de encuadre, que estandarice las múltiples definiciones, modelos teóricos y formas de medir los frames existentes. Para los estudios que incorporan la segunda acepción, "encajar en", no solo resulta aceptable sino también deseable que coexista en el campo académico una variedad de definiciones sobre qué son los frames y e/framing, dado que los conocimientos acerca de estos fenómenos y la evolución de sus definiciones conceptuales y operacionales se nutren de esa diversidad. A nivel práctico, esta postura teórica habilita al investigador a reunir significativamente aquellos conceptos y procedimientos metodológicos que necesita para producir una pieza sólida de investigación sobre una porción del proceso de encuadre (D'Angelo, 2012). Por esa razón, D'Angelo caracteriza al Framing como un programa de investigación multiparadigmático. 
En relación con su caracterización del framing como "paradigma fracturado", D'Angelo propone repensar la integralidad del framing y definirlo como un “programa de investigación multiparadigmático".

Creo que él tiene algo de razón en lo que respecta a cómo operan las ciencias sociales. Si las personas proponen sus propias definiciones de "encuadre" no alcanzaremos un paradigma unificado. Creo que no funciona de esa manera. Por otra parte, no coincido con él porque pienso que sería realmente muy útil si nos pusiéramos de acuerdo y utilizáramos el término de modo consistente, es decir, si definiéramos de manera unívoca qué es el Framing. Y, si queremos otro concepto, Ilamémoslo de otra manera. Esa es la razón principal por la que la Economía es la ciencia social más influyente y ha tenido un mayor impacto —nos guste o no- en el mundo, porque casi todos los términos tienen una sola definición en lugar de tener varios significados. Tener múltiples significados dificulta la acumulación de conocimiento. Soy un poco autoritario en este tema: para mí, la palabra schema (esquema) significa "en la cabeza" y frame (encuadre), "en el texto". Desafortunadamente, yo no puedo decidirlo, entonces, no sucede. Sigo sosteniendo que todos ganaríamos si tuviéramos un paradigma uniforme.

¿En qué paradigma colocaría, entonces, su propia investigación?: ¿en el crítico, el cognitivo o el constructivista?

Creo que por la manera en la que me refiero a este tema, podría ubicarme en todos esos paradigmas. Pienso que es una facultad importante tener una definición clara que pueda aplicarse a conceptos de modelos diferentes. No obstante, tiendo a ubicarme en el paradigma crítico, he sido bastante normativo en las preguntas que hago y en las conclusiones a las que arribo. Pero sigo pensando que toda la concepción del Framing puede adaptarse a varias disciplinas, no solamente a la comunicación. En mi caso, me identifico con el paradigma crítico, pero también con el empirista o conductista, depende de la disciplina. En Ciencia Política, sería conductista.

Precisamente, en su artículo de 1993, define el Framing como "una teoría del poder" y refuerza esta idea cuando analiza, en 2004, la relación entre gobiernos, élites políticas y medios.

Absolutamente. Como trabajo en Comunicación Política, todo se reduce al poder. Aunque si hubiera estudiado la comunicación interpersonal, también se habría reducido al poder.

E/framing process puede ser analizado desde los tres paradigmas endémicos de la investigación en comunicación - el cognitivo, el constructivista y el críticocon el objeto de alcanzar cuatro objetivos empíricos: primero, identificar los encuadres como unidades temáticas; segundo, indagar en qué condiciones se producen tales frames; tercero, examinar en qué medida activan e interactúan con el conocimiento previo de un individuo al afectar sus interpretaciones, evaluaciones y toma de decisiones; cuarto y último, analizar de manera holística 
los procesos sociales de formación de cosmovisiones alrededor de las cuestiones políticas. El paradigma cognitivo se enfoca en la "activación del conocimiento" (knowledge activation process) que los textos provocan en los esquemas individuales (Price \& Tewksbury, 1997). Desde el paradigma crítico, son concebidos como modelos persistentes de conocimiento, interpretación y presentación por medio de los cuales quienes ejercen poder social y político organizan el discurso verbal o visual (Gitlin, 2003). Para analizar el poder de los discursos, es necesario atender al contexto político y socio-cultural en el que estos encuadres nacen, se desarrollan y dejan huellas en los textos. El paradigma constructivista asume que los periodistas y otros trabajadores de prensa, inmersos en sus rutinas productivas, procesan información y, al hacerlo, crean "paquetes de herramientas" (Van Gorp, 2007) con los que interactúan audiencias activas, durante sus propios procesos de percepción e interpretación de los asuntos públicos (Reese, 2007). Según este paradigma, la cultura y el contexto actúan como "almacenes de frames" (Entman, 1993) que operan sobre los emisores -tanto en los valores individuales de los periodistas como en los intereses y posturas institucionales de los medios-y sobre sus públicos. Reese (2010) define su perspectiva como "crítico-constructivista": se asume crítico por cuanto ve los encuadres como expresiones y resultados del ejercicio del poder, y constructivista porque les otorga a los participantes del proceso - por caso, los periodistas- una autonomía relativa en la co-creación de definiciones del mundo social.

\section{Activación en cascada}

En 2004, Entman propone un nuevo modelo para analizar la relación entre gobiernos, élites políticas y medios, que se suma a estudios que estaban en agenda desde las perspectivas de la Hegemonía y de/Indexing. Para este autor, la Hegemonía no alcanza para explicar la complejidad de ciertos fenómenos en la medida en que sus parámetros analíticos no incluyen el disenso tanto político cuanto discursivo. Ergo, el abanico de temas y fuentes de información se estructurará dentro de los límites fijados por la visión dominante de dichos gobiernos y elites acerca de un asunto. Aunque la perspectiva de/Indexing sí incorpora el disenso, sus teóricos admiten que los medios, lejos de criticar la palabra oficial, actúan como un "vehículo" de la discordancia que surge entre los gobiernos y otros actores jerárquicos (Bennett, 1990; Mermin, 1999). En aquellas ocasiones en las que se abre el espectro y se introducen nuevas perspectivas, tales desviaciones respecto de la postura oficial no adquieren mayor importancia. En Projections of Power (2004), Entman parte de este punto ciego de la teoría del Indexing al analizar la capacidad que tienen los marcos interpretativos de activarse y propagarse en un sistema comunicacional estratificado, compuesto por los gobiernos, la red de élites no administrativas, las empresas de noticiasy los públicos. Puntualmente, procura comprender si los encuadres alternativos, surgidos en los estratos más bajos, logran desafiar e/ frame gubernamental. Ahora bien, cuestionar un encuadre con bocados de información mal digeridos y 
dispersos no parece suficiente. Es imprescindible promover palabras e imágenes notables, relevantes y culturalmente resonantes que sean internalizadas como una alternativa coherente al marco interpretativo que cuestionan (Entman, 2004).

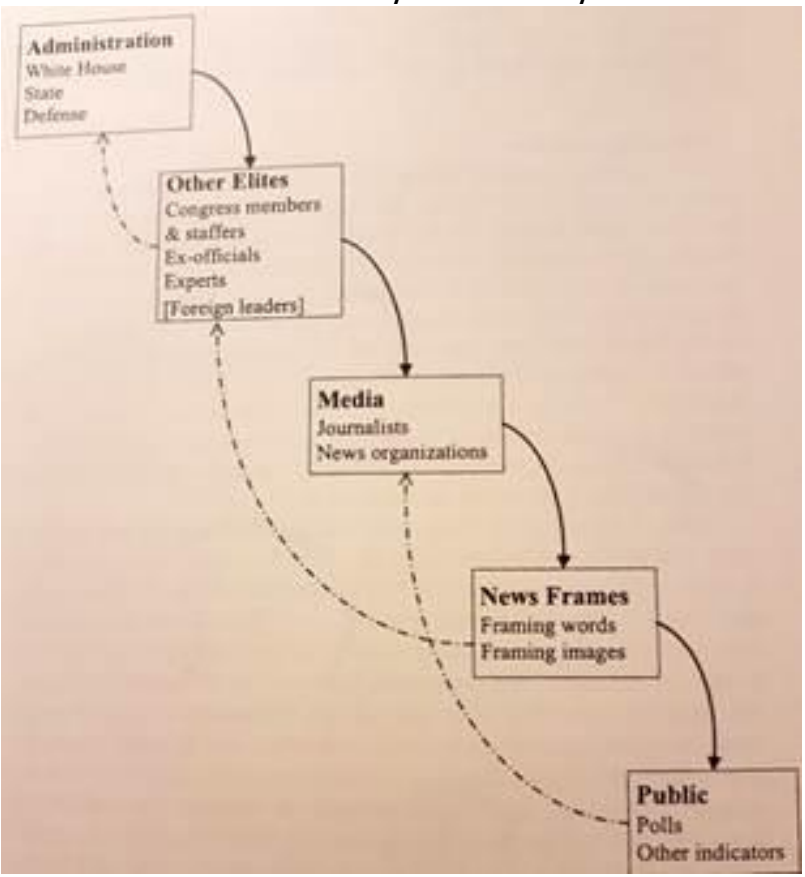

Figura 1. Modelo de Activación en Cascada.

Fuente, Entman, 2004, p. 10

\section{¿Cómo define la hegemonía para su modelo de activación en cascada?}

El problema con la teoría de la Hegemonía es que no explica realmente cómo se configuran las distintas perspectivas alrededor de un tema. Se concentra mayormente en la política exterior de Estados Unidos y formula la idea de que la actuación de los medios es funcional a los requerimientos del gobierno; todo lo demás es ruido. Supone, además, que el gobierno les ordena a los medios -en nuestros términos - cómo debe encuadrar una guerra, un conflicto o alguna cuestión relacionada con la política. Durante la guerra de Vietnam (1955-1975) no había un punto de vista hegemónico. Por el contrario, diversas perspectivas competían al mismo tiempo. Este fenómeno se escapó de la esfera de la controversia legítima, según Hallin. Sin embargo, dentro de este tema, existen muchas discusiones en torno a la estrategia del gobierno de Estados Unidos en esa guerra, tales como "debemos irnos", "debemos quedarnos" o "debemos detener el bombardeo". Por lo tanto, hubo muchos debates sobre esa guerra y sobre otras guerras en las que Estados Unidos también se involucró y en las que no hubo un punto de vista hegemónico. En Projections of Power, cuento el caso de un avión comercial que fue derribado en Rusia. En aquella circunstancia, se dio un punto de vista hegemónico que tildaba a la Unión Soviética de "mala". Asesinaron personas y eso no despertó ningún tipo de disenso. En cambio, hay eventos relativos a la política interna -sistema de salud, justicia penal, políticas para el control de armas- en los que las élites no llegaron a un acuerdo. Esos casos pueden ser analizados desde la teoría del Indexing, cuyos teóricos afirman que cuando las élites disienten, hay controversia y encuadres en competencia. La 
inquietud entonces es: ¿qué ocurre cuando hay acuerdos?, lo que puede ser respondido desde la teoría de la Hegemonía y, por otro lado, ¿qué ocurre cuando hay disputas? Si bien en este punto el Indexing admite la controversia en el interior de las elites, no alcanza a conformar una respuesta consistente para esta pregunta. Este interrogante me llevó a desarrollar los cuatro factores que explican qué sucede cuando se presenta una disputa entre los miembros de las elites. A partir de ellos, se produce una competencia entre los encuadres en la que, aunque se impone uno sobre otro, no se puede admitir que haya hegemonía en la medida en que persiste una disputa entre encuadres. En algunos casos, el resultado es más parejo y se da una condición ideal, es decir, de esta manera debería funcionar la esfera de la democracia política. Considero que ese es mi aporte, dado que la Hegemonía no logra explicar algunos de los fenómenos que ejemplifiqué aquí y el Indexing es insuficiente para determinar las causas de dichos desacuerdos.

¿Qué de esta vacancia teórica de la Hegemonía y del Indexing logra completar el modelo de Activación en Cascada para comprender cómo se organizan las voces que discrepan de la palabra oficial?

Desde mi punto de vista se puede decir que —como afirman Herman y Chomsky (1988) - seguramente existen disputas y desacuerdos, pero son marginales, triviales y no tienen ningún efecto en la política. Creo que este concepto puede ser productivo para analizar situaciones de política exterior, aunque no siempre. Sin embargo, esto no es cierto en lo que refiere a la política interior porque hay mucho debate sobre cuestiones en las que, algunas veces, el encuadre hegemónico prevalece y en otras, no. Aparecen también la competencia de encuadres y el Indexing, que determinan qué parte es la que está más fuertemente alineada con la palabra oficial. Aunque las ideas de Bennett son extremadamente útiles para entender el discurso, aun no se puede saber por qué una de las partes resulta ganadora. En esta instancia es donde funciona mi modelo de Activación en Cascada.

\section{La disputa por el encuadre}

De acuerdo con Entman (2004), la estrategia es uno de los componentes del framing process que influye en la activación y propagación del encuadre preferido de los gobiernos a otras élites, a los periodistas y sus textos, y al público. Los otros componentes son las motivaciones, la congruencia cultural y el poder. Aunque todos los miembros de las elites participan de la construcción de narrativas específicas, de la distribución o retención de información y del manejo de los tiempos, son los gobiernos centrales quienes tienen la capacidad de instalar e/frame más estable y políticamente legítimo y, por ello, suele ser más difícil ponerlo en cuestión. La forma de definir los eventos depende, en parte, de los cálculos estratégicos sobre la ventaja potencial y los beneficios futuros, promovidos fundamentalmente por las elites políticas. Una estrategia errónea puede generar una grieta en el interior de las elites, que posibilite la injerencia de 
interpretaciones alternativas por parte de miembros de la élite y periodistas opositores. En contraposición, una estrategia presidencial astuta puede fortalecer el poder de la versión oficial para penetrar en las redes de élite y seguir hacia organizaciones de noticias, periodistas $y$, finalmente, al público.

\section{¿Cómo se da la disputa por el encuadre en Estados Unidos durante la Presidencia de Donald Trump?}

Creo que depende del nivel que se observe; la oposición ha tenido la posibilidad de desafiar varios de los encuadres de Trump, en especial el que refiere al juicio político durante 2019, así como la regulación del uso de armas. Estoy analizando las diferencias entre prácticas de comunicación retóricas de la izquierda y la derecha - framing estratégico-y tratando de sugerir cómo podrían modificarse. Me pregunto, por ejemplo, si los demócratas pueden volverse más competitivos y ser capaces de desafiar el encuadre republicano, decirles: "están equivocados". Los demócratas no tienen una marca (branding) definida, están desorganizados, confundidos, temerosos y son pasivos, a tal punto que no queda claro qué representan, aunque la gente tenga una idea vaga. Los demócratas no cuentan con un mensaje claro que exprese aquello que los identifica, más allá de su carácter de opositores a los republicanos. Debo admitir que la marca de los demócratas fue creada por los republicanos. Ellos son los que tienen el mensaje -y el encuadre- más compacto y legitimado acerca de lo que representan los demócratas.

\section{¿Cómo ve la disputa de encuadres entre Demócratas y Republicanos alrededor del llamado “Travel ban"? [2]}

Esa prohibición perjudicó más a Trump de lo que lo benefició. En teoría, el modelo de Activación en Cascada debería ayudar a explicar por qué la oposición logró desafiar el encuadre de Trump referido a esta prohibición. Si recuerdo mi modelo correctamente, el componente crítico es la congruencia cultural. Que Trump declare básicamente que quiere establecer una jerarquía racial de inmigrantes, de manera que solo puedan ingresar noruegos porque es la clase de personas que se admitirán y no otras, apunta directo a nuestros valores culturales "oficiales". Quizás, nuestros valores culturales son más ambivalentes, mezclados e imperfectos. No obstante, la manera como nos queremos ver los estadounidenses a los ojos del mundo está relacionada con las fronteras abiertas, la tolerancia religiosa y, ciertamente, no queremos entrar en ninguna guerra con los musulmanes. Entonces, debido a la incongruencia cultural, el encuadre propuesto por Trump no fue exitoso. Tuvo una cobertura muy negativa, ¿cómo se puede defender la separación de padres e hijos?

Esa cuestión genera un nivel de disonancia cognitiva ${ }^{[3]}$ en la sociedad, que puede ser muy costoso políticamente.

Exacto, la mayoría no estaría de acuerdo. Pero no es el caso de Trump, porque él no comprende nada relacionado con la ética y la moralidad. Por lo tanto, son los 
medios los que refuerzan los valores de la cultura dominante. Esto no implica que Trump esté ausente, de hecho, todavía puede transmitir su mensaje. Más aun, el ala derecha conservadora afirma que la separación de padres e hijos es apenas un daño colateral de "nuestra política maravillosa, para evitar que los violadores y criminales mexicanos arruinen nuestro país". Ese encuadre, reforzado por la extrema derecha, funciona como una cámara de eco ${ }^{[4]}$ en la esfera pública, pero encuentra límites claros en algunos medios de comunicación. Por lo tanto, las dos variables más importantes son la congruencia cultural y la habilidad estratégica. Pienso que Trump es muy bueno con la segunda de estas variables, ya que, aun cuando no obtiene una aceptación generalizada de su encuadre, provoca el enojo de los Demócratas y desvía la atención. Si bien no logra instalar su encuadre, Trump es exitoso en evitar que se hable de lo importante.

Cuando el marco de un mensaje coincide con los esquemas de interpretación de las audiencias, las palabras e imágenes que articula se vuelven notables, comprensibles, memorables y culturalmente resonantes (Entman, 2004). Para que un frame sea congruente, es esencial la presencia de, al menos, dos de las cuatro funciones (elementos de encuadre) que desempeña: la definición de la situación y el remedio o la mejora futura. El primer elemento -la definición de la situación-activa los otros dos componentes: la identificación de los factores que causan el problema y la evaluación moral que lo caracteriza. Es en este punto en el que Entman enfatiza la importancia que cobra la resonancia o congruencia cultural para que un frame se instale como legítimo y políticamente estable.

\section{"Escándalo y silencio" (Scandal and Silence)}

En su libro Scandal and Silence, Entman (2012) indaga las razones por las cuales algunas conductas deshonestas alcanzan el estatus de escándalo político, mientras que otras, igual o más dañinas, no son encuadradas en esos términos y se las ignora. En otras palabras, Entman se pregunta por los procesos que desatan escándalos y les otorgan un significado político, lo cual lo lleva a plantear la necesidad de contar con un concepto robusto de "escándalo" que incorpore aquellas transgresiones que, lejos de mantenerse en el tiempo, se desinflan sin generar impacto en el sistema político ni captar la atención del público. Entman (2012) parte de la premisa de que existe un desfase entre el tratamiento que los medios hacen de los escándalos, así como el grado de atención que les otorgan, por un lado, y los costos sociales profundos del mal comportamiento oficial, por el otro. Sin embargo, advierte que las organizaciones de noticias tampoco tienen un total control del curso que toma la narrativa mediática de los escándalos. Más aun, en aquellas ocasiones en las cuales la dirigencia de distintas fuerzas políticas comparte la responsabilidad sobre un comportamiento potencialmente escandaloso, es menos probable que dicho evento sea encuadrado en esos términos. Por el contrario, su tratamiento fugaz y confuso impedirá que penetre 
en la conciencia pública y, por ende, que influya en la dinámica política. A menos que otros actores influyentes promuevan un estado de indignación, la mayoría será renuente a sumergirse en posibles escándalos que amenacen seriamente los intereses de individuos poderosos. Por cierto, que la publicitación de un escándalo no necesariamente implica destapar un secreto. Lo que importa en esas circunstancias es que esos malos actos se encuadren como escándalos. A la luz de lo dicho, el autor pone en cuestión la idea extendida de que los escándalos políticos restituyen los estándares morales de una sociedad y patrullan sus límites. Por el contrario, las dificultades que los medios tienen para llegar a la raíz de los malos comportamientos permiten afirmar que los escándalos diluyen las fronteras de lo moralmente aceptable.

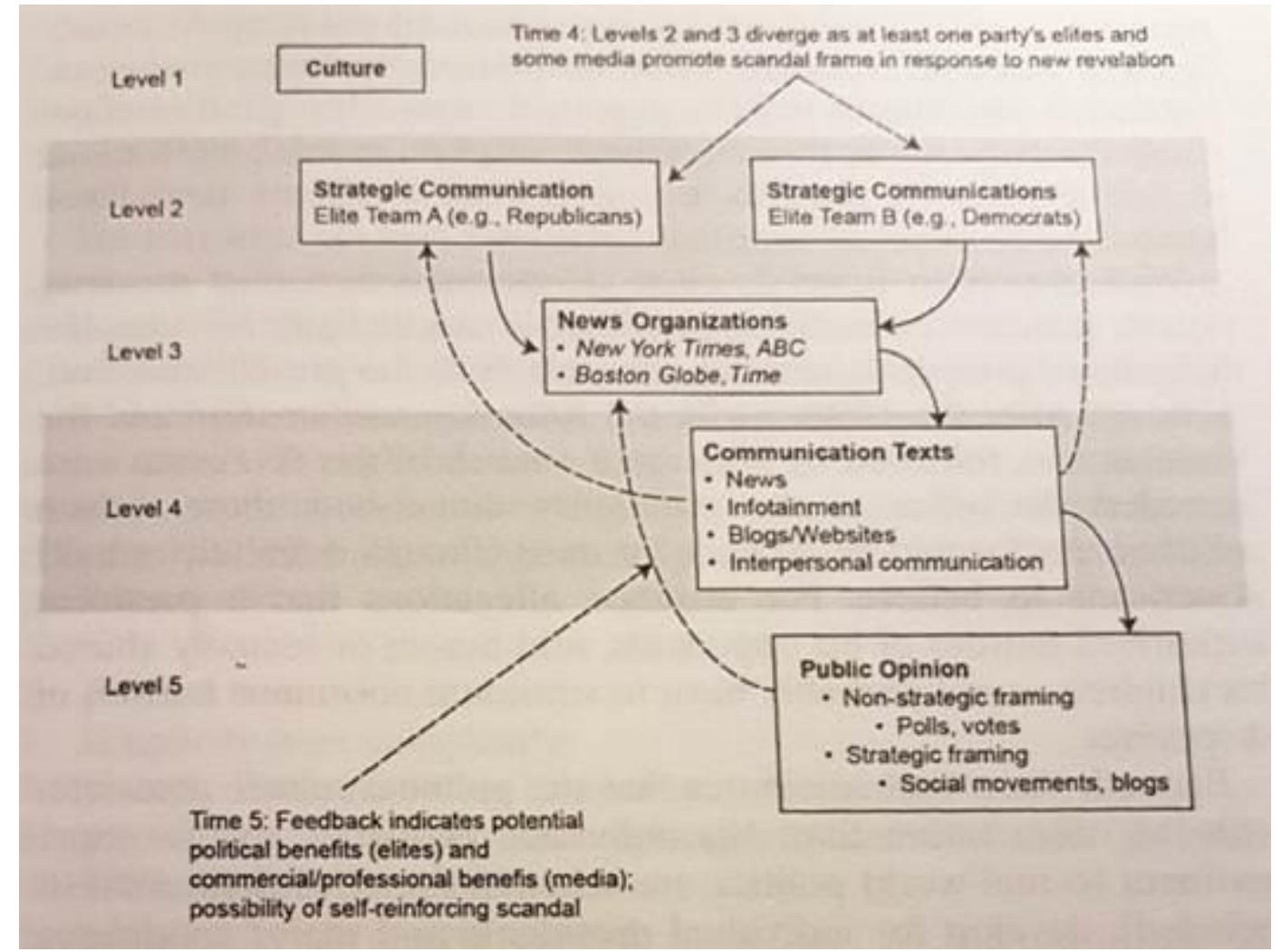

Figura 2. Activación en Cascada en Red.

Fuente: Entman, 2012, p. 37.

¿Qué diferencias podría establecer entre la concepción del modelo de Activación en Cascada que desarrolla en Projections of Power (2004) y la competencia de encuadres en el caso de los escándalos (Entman, 2012)?

Existen dos dimensiones en el análisis de los escándalos locales: una que se relaciona con el tamaño del escándalo y la otra, con la forma de encuadrarlo. Para la persona que es el centro del escándalo, el primer objetivo es evitar que se convierta en noticia, aunque ello no suponga necesariamente querer imponer un encuadre. Si la información se hace pública, entonces, se busca encuadrarla. Trump es un claro ejemplo de cómo es posible minimizar un escándalo y 
convertirlo en una discusión trivial. En el diagrama que ilustré en mi libro Scandal and Silence (2012) [ver Figura 2], se observa una forma más multidimensional del flujo de los encuadres en cascada. Allí, además, hablo de distintos niveles en el sistema y los diferencio más claramente. Creo que es un avance que ayuda a hacer el modelo más exacto. Para adoptar o adaptar el modelo al mundo de las redes sociales, propuse un nuevo diagrama en 2018 (Entman \& Usher, 2018) [Ver figura 3], llamado "Activación en Cascada en Red" (Cascading Network Activation), que considero más apropiado, ya que contiene las cinco válvulas digitales (plataformas, análisis, algoritmos, medios ideológicos y actores deshonestos) que bombean la información y el flujo de encuadres sociopolíticos. En este marco, en referencia al concepto de hegemonía, creo que es realmente muy difícil sostener la idea de un encuadre único, sin importar cuál fuere; siempre habrá encuadres alternativos circulando y poniendo en cuestión la palabra oficial.

Teniendo en cuenta que en Projections of Powerson los medios tradicionales los que inician el contra-encuadre en el marco del 11-S, ¿cómo ve la relación entre las elites políticas y los medios tradicionales en el esquema que usted propone para el análisis de los escándalos?

Los Republicanos y los conservadores llevan a cabo una campaña desde hace 40 o 50 años para deslegitimar a los medios de comunicación. Los periodistas más importantes trataron de esforzarse por buscar la "verdad". Al deslegitimarlos, la verdad se convierte en una categoría más contingente y relativa, y esta situación termina siendo ventajosa para esas fuerzas políticas. En el progresivo acercamiento de los Republicanos a la derecha, su conexión con los hechos reales se hizo cada vez más imprecisa. De hecho, muchos de los contenidos que se incluyen en los encuadres no tienen asidero; por caso, el peligro de la inmigración o los beneficios de reducir los impuestos a los ricos. La eficacia de su discurso reside en su persistencia en estos encuadres desde 1981 [N. de las A.: alude al escándalo político definido como "Watergate"].

En escenarios comunicacionales sumamente concentrados y con poca diversidad en los mensajes, ¿dónde ubicaría a los medios de élite en el esquema estratificado desarrollado en Projections of Power?

Siguiendo la manera en la que desarrollé el diagrama, ubicaría a los medios debajo de los líderes políticos, aunque entre figuras mediáticas y políticas hay una relación bastante simbiótica. ¿Quién es más poderoso, el editor del The New York Times o algún miembro de rango intermedio del Congreso? Seguramente el editor del The New York Timesy, tal vez, algunos de sus columnistas. Más concretamente, Maggie Haberman, una de las periodistas más importantes en la Casa Blanca, tiene más poder para influir en lo que piensa la gente de Trump que la mayoría de los miembros Demócratas del Congreso.

\section{Los periodistas son celebridades cuyas definiciones influyen en la opinión pública.}

Ahora hay más niveles, hay más caminos. Por lo tanto, no es tan sencillo llevar a cabo investigaciones y escribir sobre eso. Mi colega, Steve Livingston, dice que mi 
diagrama de Activación en Cascada es "barroco". Y yo le pregunté si había dicho "broke"(de broken, roto en inglés) y me contestó que eso también. Pienso que los medios tradicionales le han cedido algo de su poder a las redes sociales. En la actualidad, la legitimidad que solían ostentar determinadas fuentes se ha diluido, ya que es lo mismo decir "lo vi en Twitter" o "lo leí en el New York Times". El nivel de probabilidad de que algo sea verdad se relaciona con frases como "un amigo lo publicó en Twitter y yo lo conozco y confío en él". Pero lo más importante es la polarización: no hay una esfera común, sino dos mundos de hechos y emociones contrapuestos entre los Demócratas y los Republicanos. En 1974, casi todos los Demócratas votaron a la par de los Republicanos para demostrar que eran leales a la democracia y la Constitución. Eso ya no existe, hoy, ningún Republicano defiende esos valores.

\section{Activación de Frames en red}

En el análisis de Entman (2004), la activación selectiva de ciertos elementos de encuadre y el consecuente desafío a la interpretación oficial discurren en un sistema comunicacional estratificado, compuesto por niveles. En 2018, Entmany Usher proponen revisar ese modelo lineal; se preguntan si las válvulas digitales democratizan el flujo comunicacional al erosionar las jerarquías en el control de la información o si, por el contrario, afianzan las estructuras dominantes y consolidan la fragmentación social y la polarización política. En este sentido, debemos observar que, en las redes sociales, la lógica de circulación de los mensajes difiere del modelo estratificado descripto en Projections of Power. Los mensajes circulan de manera dinámica, pues los usuarios tienden a vincularse con quienes comparten valores, de tal modo que estructuran comunidades homogéneas. A partir de la atención selectiva y de la activación de determinados contenidos, los usuarios tejen recorridos con los que producen combinaciones particulares en distintas regiones de la red y conforman marcos interpretativos locales (Aruguete, 2019). Dichos enlaces no siguen una lógica jerárquica predeterminada, sino que se traban en función de jerarquías enredadas. En esta línea, la mirada integral delframing process contempla la lógica orgánica de la red tanto como el comportamiento subjetivo de los usuarios, en cuyos esquemas psíquicos se activan determinados pensamientos en detrimento de otros. 


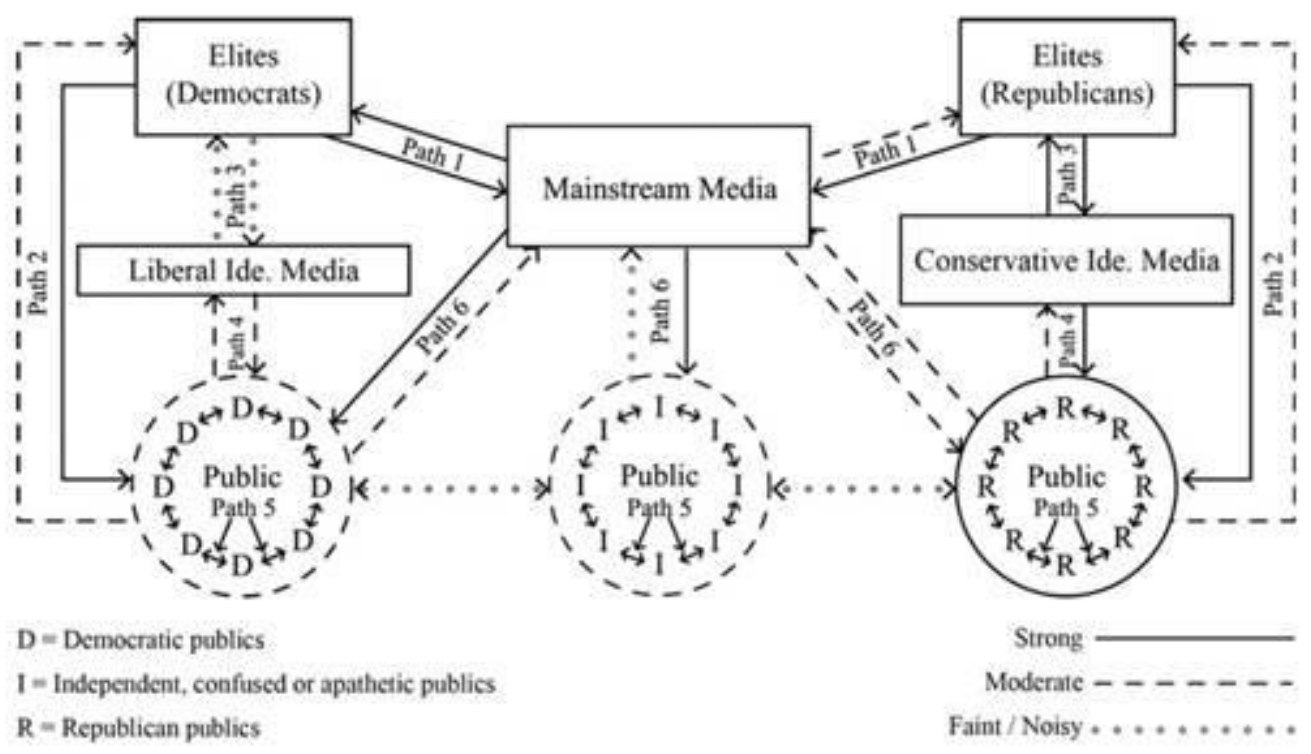

Figura 3. Activación en Cascada revisada.

Fuente: Entman \& Usher, 2018, p. 303.

Usted mencionó que el poder de imponer encuadres todavía está en manos de los gobiernos y de las elites políticas en este nuevo escenario comunicacional. Estamos lejos de pensar que habitemos un ambiente democrático en las redes sociales, ciertamente hay más jerarquías que antes. Ahora bien, ¿qué piensa de las relaciones entre usuarios de bajo rango y de ellos con los gobiernos y las elites políticas, en las redes sociales? Usted creó en su trabajo de 2018 (Entman \& Usher, 2018) un esquema distinto del que propone en Projections of Power.

En el pasado, lo único que había que hacer era monitorear los medios de comunicación más grandes para obtener una idea de qué pensaba el público en general. En la actualidad, hay grupos dispersos de esferas que deben ser monitoreados. Siempre fue difícil estudiar la esfera de los líderes, cómo piensan, cómo forjan sus encuadres en la sociedad. Aún hoy lo es, pero ahora hay una pequeña ventaja, y es que están en Twitter y tienen páginas de Facebook, y, de alguna manera, anuncian "estos son los encuadres que quiero que uses y que te hagan pensar de esta manera". Así que, tal vez, esto lo hace un poco más accesible. Estoy tratando de resumirlo, todavía hay mucha investigación por hacer.

De acuerdo, pero los frames nunca se anuncian explícitamente. En general, hay que indagar en las ideas latentes que orientan esas expresiones.

Es cierto, pero yo me refiero a lo siguiente. Al tener estos nuevos caminos, los líderes pueden comunicarse con el público directamente sin la mediación de los medios tradicionales de comunicación; y ese público, a su vez, puede comunicarse entre sí de manera masiva. También existe la comunicación directa entre los líderes y los públicos mediante Twitter, por ejemplo. Los periodistas lo monitorean constantemente para conocer lo que piensa el público, que sin duda está bastante distorsionado pero que forma un encuadre en la opinión pública. 
Por lo tanto, se producen nuevos flujos de influencia. Esa es la diferencia. Para mí, no hay actualmente un aplanamiento de las jerarquías, ya que Trump y otros políticos tienen la habilidad de promover mentiras y de utilizar las redes sociales para sus estrategias de desinformación. Solíamos tener una esfera pública combinada en la que la gente creía una historia sin dudar, como, por ejemplo, la cuestión del calentamiento global. Ahora, las personas, que se comunican entre sí y con las élites sin que medien los periodistas, expresan que no existe tal calentamiento...

¿Considera que esta situación se relaciona con la disminución de los niveles de credibilidad de los medios tradicionales?

Sí.

Frente a esa caída en la reputación de los medios tradicionales, ¿cuál es o cuáles son los nuevos actores con poder de imponer su definición de la situación?

Sigo pensando que son los líderes políticos más importantes, como los funcionarios de más alto rango del gobierno y los líderes de la oposición, aun cuando en la actualidad exista más comunicación desde las bases hacia arriba, por lo que los líderes deben adoptar o adaptar ciertas medidas. No obstante, si no lo hacen, no importa demasiado. Lo que es realmente interesante es que ahora existe Facebook, que, mediante sus algoritmos, determina muchas de las noticias que se dan a conocer. Yo no estoy en Facebook, me niego a aparecer en Facebook, pero un porcentaje muy alto de personas recibe noticias desde ahí. Todas las noticias pasan por un filtro que resuelve cuáles se publican y cuáles no. Los algoritmos detectan, por ejemplo, que una persona es conservadora y que, por ende, recibirá un tipo determinado de noticias. Esta programación informática es la que decide los contenidos que se van a visibilizar. Que lo hagan los seres humanos no es la solución perfecta, porque los seres humanos somos parciales y limitados, pero usar algoritmos que no sabemos cómo funcionan tampoco me parece que sea bueno.

\section{¿Podemos seguir hablando de percepción selectiva ${ }^{[5]}$ en este nuevo escenario mediático?}

Creo que la percepción selectiva es fundamental para la psiquis, para mantenerse sano. La diferencia está en que ahora las percepciones son coherentes con lo que circula en el interior de la burbuja; de esta forma, nunca será puesta en riesgo. Por otro lado, cuando había una sola esfera compartida, ya se hablaba de percepción selectiva. Ahora bien, en sociedades polarizadas como la de Estados Unidos, ya sabemos que existe entre un 30 y un 40 por ciento de personas que vota a cualquier Republicano, incluso a alguien tan corrupto e incompetente como Trump. De la misma manera, sabemos que otro 40 por ciento vota a cualquier Demócrata que se enfrente a cualquier Republicano. Seguimos estudiando esos dos grupos en lugar de estudiar al 20 por ciento restante, que parece tener una mezcla confusa acerca de las lealtades políticas. En Estados Unidos, se observa un apoyo apabullante al incremento en los impuestos a los ricos. Incluso los Republicanos apoyan esta medida. Al mismo 
tiempo, otra iniciativa propuso aplicar un impuesto plano (flat tax) de entre el 10 y el 15 por ciento sobre los ingresos de toda la población, y también obtuvo un apoyo apabullante. ¿Cómo hacer para aumentar el impuesto a la riqueza si se reduce el valor de los impuestos? Evidentemente, hay personas que están confundidas y no logran distinguir las contradicciones. Ese grupo de personas, que podemos ubicar aproximadamente en el centro, es al que debemos tratar de entender mejor en lo que refiere a las decisiones que toman, por ejemplo, si votan a Trump. Mucha gente que en 2012 votó a Obama, en 2016 votó a Trump. No tiene sentido, a menos que hayas sufrido algún trastorno de personalidad o te hayas convertido en billionario en esos últimos cuatro años. ¿Por qué hacen eso? Creo que es vital entenderlo. Creo, además, que algo similar ocurrió en la Argentina.

\section{Referencias}

Aruguete, N. (2019). Network-Activated Frames (NAF), Redefining Framing in a New Digital Era. Encyclopedia of Educational Innovation. Springer Nature: Singapore.

Bennett, W. L. (1990). Toward a Theory of Press-State Relations in the United States. Journal of Communication, 40(2), 103-127. https://doi.org/10.1111/j.1460-2466.1990.tb02265.x.

Berelson, B., Lazarsfeld, P. y McPHee, W. (1954), Voting. A study of opinion formation in a presidential campaign. Chicago: University of Chicago Press.

D'Angelo, P. (2012). Studying Framing in Political Communication with an Integrative Approach. American Behavioral Scientist, 56(3), 353-364. https://doi.org/10.1177/0002764211426332.

Entman, R. M. (1993). Framing: Toward Clarification of a Fractured Paradigm. Journal of Communication, 43(4), 51-58. https://doi.org/10.1111/j.14602466.1993.tb01304.x.

Entman, R. M. (2003). Cascading activation: Contesting the White House's frame after 9/11. Political Communication, 204), 415-432. https://doi.org/10.1080/10584600390244176.

Entman, R. M. (2004). Projections of power: Framing news, public opinion, and US foreign policy. Chicago: University of Chicago Press.

Entman, R. M. (2012). Scandal and Silence. Media Responses to Presidential Misconduct. Malden: Polity Press.

Entman, R. M., \& Usher, N. (2018). Framing in a Fractured Democracy: Impacts of Digital Technology on Ideology, Power and Cascading Network Activation. Journal of Communication, 68(2), 298-308. https://doi.org/10.1093/joc/jqx019.

Festinger, L. (1962). A Theory of Cognitive Dissonance, vol. II. Stanford: Stanford University Press. 
Gitlin, T. (2003). The Whole World Is Watching Mass Media in the Making and Unmaking of the New Left $\left(2^{\circ}\right)$. California: University of California Press.

Herman, E. y Chomsky, N. (1988). Manufacturing Consent: The Political Economy of the Mass Media. New York: Pantheon.

Key, V. O. (1966). The Responsible Electorate. Cambridge: Belknap.

Klapper, J. (1986). La efectividad de la comunicación masiva. En Graber, D. (ed.). El poder de los medios en la política, pp. 37-50. Buenos Aires: Gel.

Matthes, J. (2012). Framing Politics: An Integrative Approach. American Behavioral Scientist, 56(3), 247-259.

https://doi.org/10.1177/0002764211426324

Mermin, J. (1999). Debating War and Peace: Media Coverage of U.S Intervention in the Post-Vietnam Era. Princeton: Princeton University Press.

Neuman, W. R., Just, M. R., \& Crigler, A. N. (1992). Common Knowledge. News and the Construction of Political Meaning $\left(1^{\circ}\right)$. London: The University of Chicago Press.

Peter, J., Semetko, H., \& de Vreese, C. H. (2003). EU Politics on Television. European Union Politics, 4(3), 305-327.

Price, V., Tewksbury, D., \& Powers, E. (1997). Switching Trains of Thought: The Impact of News Frames on Readers' Cognitive Responses. Communication Research, 24(5), 481-506. https://doi.org/10.1177/009365097024005002.

Reese, S. D. (2007). The Framing Project: A Bridging Model for Media Research Revisited. Journal of Communication, 571), 148-154. https://doi.org/10.1111/j.1460-2466.2006.00334.x.

Reese, S. D. (2010). Finding Frames in a Web of Culture: The Case of the War on Terror. (P. D'Angelo \& J. Kuypers, eds.), Doing News Framing Analysis: Empirical, Theoretical, and Normative Perspectives, pp. 17-42. New York: Routledge. https://doi.org/10.4324/9780203864463.

Scheufele, D. A. (1999). Framing as a Theory of Media Effects. International Communication Association, (August 1996), 103-122.

Semetko, H. A., \& Valkenburg, P. M. (2000). Framing European politics: a content analysis of press and television news. Journal of Communication, 50(2), 93109. https://doi.org/10.1111/j.1460-2466.2000.tb02843.x.

Van Gorp, B. (2007). The Constructionist Approach to Framing: Bringing Culture Back In. Journal of Communication, 57(1), 60-78.

https://doi.org/10.1111/j.1460-2466.2006.00329.x. 

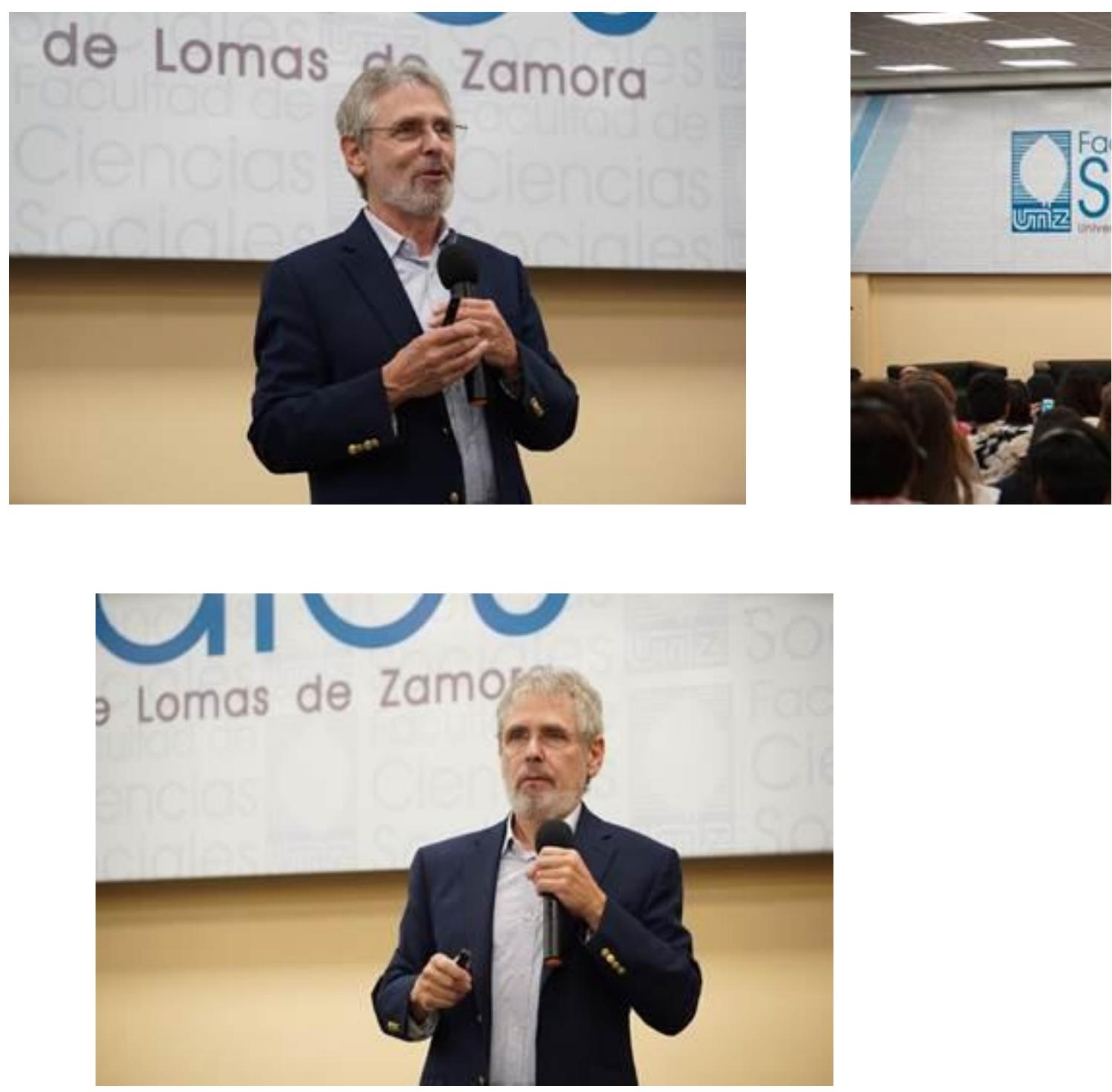

[1] Las funciones de encuadre a las que se refiere Entman están contenidas en la siguiente definición: (Encuadrar) "implica seleccionar y realzar algunos aspectos de eventos o temas, y hacer conexiones entre ellos para promover una interpretación, evaluación y/o solución. Las palabras e imágenes que componen un encuadre pueden ser distinguidas de las demás noticias por su capacidad para estimular apoyo u oposición a los distintos campos de un conflicto político" (Entman, 2003, p. 417).

[2] El 27 de enero de 2017, el presidente de los Estados Unidos Donald Trump firmó la Orden Ejecutiva número 13769, titulada “Protección de la Nación contra la Entrada de Terroristas Extranjeros en Estados Unidos". Esa normativa limitó fuertemente el viaje y la inmigración de personas de varios países de Oriente Medio, y suspendió el Programa de Admisión de Refugiados de los Estados Unidos, así como la entrada de personas de siete países de mayoría musulmana (Libia, Irán, Irak, Suecia, Somalia, Sudán, Siria y Yemen), sin importar el estatus de visado o residencia permanente.

${ }^{[3]}$ La hipótesis de la disonancia cognitiva propuesta por Festinger (1962) establece que los individuos evitan información incómoda que cuestione sus valores o actitudes mientras que se acercan a aquella que es coherente con sus creencias y esquemas de percepción.

[4] El término "cámara de eco" (Key, 1966) alude al modo en que los votantes resignifican y adhieren al discurso político de las élites. En redes sociales, se usa para describir el modo en que ideas o cualquier tipo de información es amplificada por una comunidad de usuarios, lo que deviene en una versión "mejorada" de sus propios prejuicios. En palabras de Key $(1966$, p. 2) lo que sale de una cámara de eco "guarda una relación inevitable e invariable con lo que entra en ella". 
[5] La exposición y la percepción selectivas, afirma Klapper (1986), sugieren que las personas atienden, se exponen y perciben aquello que es consistente con sus creencias y puntos de vista. Según esta tesis, la exposición a los medios solidifica preferencias, "cristaliza y refuerza más que convierte" (Berelson,

Lazarsfeld y McPhee, 1954, p. 248). 